Check for updates

The BMJ

Cite this as: $B M J 2021 ; 373: n 1513$ http://dx.doi.org/10.1136/bmi.n1513 Published: 15 June 2021

\title{
Delta variant: What is happening with transmission, hospital admissions, and restrictions?
}

\author{
More than 71 million doses of covid-19 vaccine have been administered in the UK, and in many areas \\ lockdown has eased. But, as the delta variant dominates, Elisabeth Mahase asks: is another wave \\ on the horizon?
}

\section{Elisabeth Mahase}

\section{Are covid-19 hospital admissions increasing?}

Yes. The number of new cases of covid-19 has been rising in the UK for the past few weeks, and admissions of patients to hospital are following suit. As of 9 June the number of people in hospital each day with covid-19 exceeded 1000, after having fallen to the hundreds in the middle of May after the previous wave.

\section{Is this because of the delta variant?}

Cases were expected to rise at least a little as restrictions eased, but the new delta variant seems to have complicated matters. ${ }^{2}$ Public Health England figures show that the variant now accounts for $90 \%$ of UK cases, with the total number exceeding 42000. Research indicates that delta is associated with an estimated $60 \%$ higher risk of household transmission than the alpha variant, which was already much more transmissible than the original version of the virus. There are also suggestions that delta could carry a much higher risk of hospital admission.

Speaking to the BBC on 13 June, Andrew Hayward, an adviser to the government's Scientific Advisory Group for Emergencies (SAGE) and professor of infectious disease epidemiology at University College London, said, "I think it's now very clear that we will have a substantial third wave of covid infections. The really big question is how much that wave of infections is going to translate into hospitalisations. The fact that we've got $55 \%$ of the adult population double vaccinated means that this will be substantially less bad than it could have been, but we still don't know exactly how bad it could be.

"Sixty per cent more infectious is extremely worrying - that's the main thing that will drive the speed with which the next wave comes along. And the fact that the level of hospitalisations from this infection appear to be maybe up to double those of the previous infection is of course also extremely concerning."

Another concern is that the covid vaccines seem to be less effective against the delta variant, especially after one dose. A PHE preprint found that the Pfizer-BioNTech vaccine was $88 \%$ effective and the Oxford-AstraZeneca 60\% effective against the delta variant two weeks after the second dose, but both vaccines were only $33 \%$ effective against symptomatic disease from delta three weeks after the first dose. ${ }^{3}$ However, the most recent PHE analysis of 14019 delta cases (14 June) indicates that two doses of either vaccine are still highly effective against hospital admission: $96 \%$ for Pfizer-BioNTech and 92\% for Oxford-AstraZeneca. ${ }^{4}$

Speaking at a Science Media Centre briefing on 9 June, Neil Ferguson, director of the Medical Research Council's Centre for Global Infectious at Imperial College London, said, “There's still quite a lot of uncertainty about what the vaccine efficacy against the delta will be for those more severe forms of disease. It's well within the possibility that we could see another third wave, at least comparable in terms of hospitalisations, maybe not as severe as the second wave.

“Almost certainly I think that deaths probably will be lower. The vaccines are having a highly protective effect, and cases in hospital are milder, but still it could be quite worrying. There is a lot of uncertainty."

\section{What is different about the delta variant?}

In some ways the delta variant is an "improved" version of the alpha variant, making it more easily transmissible and more of a concern.

Speaking at the Science Media Centre briefing, Wendy Barclay, professor of virology and head of infectious disease at Imperial College London, explained, "The delta variant has got two important mutations in its spike protein, or sets of mutations. One is at the furin cleavage site, which we think is quite important for the fitness of the virus in the airway. The virus that emerged in Wuhan was suboptimal in that respect, so it transmitted, but perhaps not as well as it might. The alpha variant took one step towards improving that with a certain mutation, and the delta variant has built on that and taken a second step now, a bigger step, towards improving that feature."

\section{Why is delta able to transmit more easily?}

Barclay said that the current data indicated that the virus was "fitter in human airway cells," meaning an increased amount of the virus in the infected person, and so they may expel more virus out into the air to pass on to the next person. This is supported by the testing data, which show that the CT value (cycle threshold)-the number of amplification cycles needed for the virus to be detected-seems to be lower in samples from delta infected people, meaning they contain more virus.

Another suggestion is that if this variant is better at infecting human airway cells, people may become infected after a lower exposure. 


\section{Does delaying the easing of covid-19 restrictions make a difference?}

Yes, because it allows more people to receive two doses of the vaccine. Barclay said, “Any delays, just from a purely scientific basis, will help, because they will allow more time for people to get the second dose. And also just having the second dose is not quite enough. You need to get around seven days after the second dose for the vaccine to really boost the immune response up to the levels that you'd like it to be."

The final stage of lockdown easing in England, which had been expected to be on 21 June, has now been delayed to 19 July.

\section{Even if the death rate with delta is lower, could the healthcare system still be overwhelmed?}

Absolutely. Rising hospital admission rates would increase pressure on the already exhausted health system and could overwhelm it. Writing in BMJ Opinion, the chief executive of NHS Providers, Chris Hopson, said, "Given current NHS pressures, any increase in covid-19 admissions will set back progress on tackling the care backlog. Are we ready to accept this trade off?"5

This message has been echoed by other health leaders, including NHS Confederation deputy chief executive Danny Mortimer, who told the media the current situation was "extremely precarious."

He said, "Health leaders are all too aware that rising infections, and especially at such a rapid rate, can easily lead to major rises in hospital admissions. Even a slight increase in admissions will affect capacity and could put recovery efforts at risk. Covid-19 hospital admissions are already going up, and that will put capacity under strain, especially as the latest performance figures showed 5.1 million people are waiting to start treatment."

\section{Are more children becoming ill?}

There are no official figures on this, although leaders in the area of child health have refuted suggestions made by members of the Scottish government that children were now more at risk from covid-19 and that many had been admitted to hospital.

Steve Turner, Royal College of Paediatrics and Child Health registrar and consultant paediatrician at Royal Aberdeen Children's hospital, said, "As it stands there are very few children in hospital in Scotland and across the whole of the UK due to covid. We're not seeing any evidence of an increase in paediatric admissions with covid. A very small number of admissions who test positive for covid is what we'd expect.

"Our experience over the last 15 months is that many children who test positive have come into hospital for something else, like broken bones. At the moment the situation in the UK is stable. The number of children in hospital with covid remains very low." 6

\footnotetext{
Coronavirus (covid-19) in the UK. 13 Jun 2021. https://coronavirus.data.gov.uk/details/healthcare. Public Health England. Variants: distribution of case data, 11 June 2021.

https://www.gov.uk/government/publications/covid-19-variants-genomically-confirmed-casenumbers/variants-distribution-of-case-data-11-june-2021.

3 lacobucci G. Covid-19: Single vaccine dose is 33\% effective against variant from India, data show. BMJ 2021;373:n1346. doi: 10.1136/bmj.n1346 pmid: 34035039

4 Public Health England. PHE monitoring of the effectiveness of covid-19 vaccination. 26 May 2021 https://www.gov.uk/government/publications/phe-monitoring-of-the-effectiveness-of-covid-19vaccination.

5 Hopson C. Should covid-19 restrictions be relaxed on 21 June? We need to look at the stark realities. BMJ Opinion. 9 Jun 2021. https://blogs.bmj.com/bmj/2021/06/09/chris-hopson-shouldcovid-19-restrictions-be-relaxed-on-21-june-we-need-to-look-at-the-stark-realities.

6 Maishman E. Covid in children: "No evidence" of increase in hospital numbers, say paediatricians Edinburgh Evening News. 3 Jun 2021. https://www.edinburghnews.scotsman.com/health/covid-
} in-children-no-evidence-of-increase-in-hospital-numbers-say-paediatricians-3259535.
This article is made freely available for use in accordance with BMJ's website terms and conditions for the duration of the covid-19 pandemic or until otherwise determined by BMJ. You may use, download and print the article for any lawful, non-commercial purpose (including text and data mining) provided that all copyright notices and trade marks are retained. 